\title{
Nutritional Guidelines for School Lunch Programs: A Survey of Islamic Schools and Recommendations for Creating a Culture of Healthful Eating
}

\author{
Sumiya Khan, MS, RD, CDN;1 Ziena Saeed, BS, RD;2 Hanifa Hameed Diwan, BS, RD;3 \\ Iqra Hussain; 4 Sarah Amer, MS, RD, CDN;5 Mohamed M. Haq, MD 6 \\ ${ }^{1}$ Chair-Elect, Muslims in Dietetics and Nutrition (MIDAN), Hamden, Connecticut; \\ 2Program Manager, USDA Nutrition Education Program, Greater Lansing Islamic School \\ East Lansing, Michigan; \\ ${ }^{3}$ Consultant Dietitian, Dallas, Texas; \\ ${ }_{4}^{4}$ Undergraduate Student, University of Houston, Houston, Texas; \\ ${ }^{5}$ Ramsey, New Jersey; \\ ${ }^{6}$ Chairman, Public Health Committee, IMANA, Houston, Texas
}

\begin{abstract}
Objective: To determine the status of lunch programs in Islamic schools in the United States and develop recommendations for improving them.

Study Design: The Islamic Medical Association of North America (IMANA) conducted a survey of lunch programs by mailing questionnaires to 100 Islamic schools in the United States. Muslims in Dietetics and Nutrition (MIDAN) developed lunch menus using American and ethnic foods conforming to nationally recommended guidelines.

Results: Forty-eight Islamic schools responded to the survey, revealing that 20 schools follow guidelines and only six have dietitians advising on menu planning. Based on this survey, IMANA, with the assistance of MIDAN, has developed a summary of guidelines that schools can follow. These guidelines include sample menus of American and ethnic foods, recommendations for creating a n environment for healthful eating, and sources for funding school lunch programs.

Conclusions: IMANA and MIDAN, recognizing the scientific significance and religious relevance of a nutritious diet, have developed these recommendations. This information is provided to aid Islamic schools in implementing guidelines for nutritionally balanced school lunch menus and in creating a culture that fosters a healthful lifestyle.
\end{abstract}

Keywords: Lunch program, Islamic school, nutritional guidelines.

http://dx.doi.org/10.5915/43-2-8276

Introduction

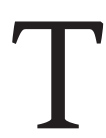
he Pew Research Center report from 2007 estimated there are 800,000 Muslim children under the age of $18 .^{1}$ Recent data reveal that nearly

Correspondence should be directed to

Mohamed M. Haq, MD

mohamedmhaq@yahoo.com one in five school-age children in the United States is obese. ${ }^{2}$ A balanced diet is essential to optimize physical and cognitive child development. ${ }^{3}$ Obese children are at a higher risk for medical and psychological illness and social stigma. ${ }^{4}$ Children who consume excess fats, refined sugars and decreased amounts of fruits, vegetables, and whole grains have an increased risk of obesity, heart disease, and other illnesses. ${ }^{3}$ Poor diet not only impacts a child's physical 
health, but it can also decrease his or her academic performance. Several studies document that undernourished and micronutrient-deficient children perform poorly at school. 5

The Muslim community in North America has been active in the last several years developing fulltime Islamic schools to integrate an academic education in an Islamic atmosphere. As Islamic schools are new and limited in resources compared to the public education system, their primary attention has been on academics and Islamic knowledge and culture.

A large amount of literature on nutrition in public schools exists. ${ }^{6}$ Kubic et al reported on the dietary practices of alternative high schools in Minnesota. ${ }^{7}$ However, they did not specifically name any Islamic schools in their data. A MEDLINE search of lunch programs in Islamic schools revealed no publications.

A survey was initiated due to the lack of information about this important aspect of child development in Islamic schools. The data gathered was used to develop recommendations based on nationally recommended guidelines.

\section{Materials and Methods}

A MEDLINE search of the literature for data on nutritional guidelines for children, school lunch programs, culture of healthful eating, and funding for school lunch programs was performed. A survey questionnaire (Appendix 1) was mailed to all the Islamic schools in the United States whose addresses were found on the Internet.8 United States Department of Agriculture (USDA) national guidelines for school lunches were reviewed. IMANA partnered with Muslims in Dietetics and Nutrition (MIDAN), a Member Interest Group of the American Dietetic Association, to develop dietary recommendations based on national guidelines from the USDA and the Department of Health and Human Services (HHS).

\section{Results}

The survey letter was mailed to 100 schools, and 48 schools responded. Fifty-eight percent of the schools surveyed serve lunch. Forty-eight percent of schools serving lunch have a set menu. Only 24 percent of schools serving lunch follow USDA-recommended guidelines.

Of the schools that do not serve lunch, 46 percent provide guidelines for parents to follow. Twenty-one percent of schools that serve lunch have received advice from dietitians regarding meal planning. All but two schools providing lunch served both American and ethnic food. Only four schools provided a copy of their lunch menu. An overwhelming majority, 87 percent, was interested in receiving recommendations for a nutritionally balanced lunch menu created by a dietitian. In response, IMANA and MIDAN have developed the guidelines in Appendix 2, which describes the basic requirements for school lunches based on the National School Lunch Program.9-13 Although many students who attend Islamic schools in the United States may be comfortable consuming typical American foods, some schools may prefer offering ethnic food choices to students. Based on the current national guidelines, MIDAN created sample menu for both American and ethnic foods (Appendix 3). In addition to dairy foods, these suggestions can be used to meet the Minimum Nutritional Requirements for School Lunches (Appendix 2).

\section{Discussion}

Lunch provides approximately 30 percent of the daily caloric needs of school-age children. Islamic schools have an excellent opportunity to nourish children's bodies and minds while following the principles of Islam. It also is the ideal place to teach children healthful dietary habits, including consuming nutritious foods and avoiding junk foods. Proper Islamic etiquettes, including supplication prior to eating and sanitary measures such as hand washing, can also be taught in this setting.

Islam recognized the importance of a balanced diet hundreds of years before scientific research noted its relevance. The Qur'an says:

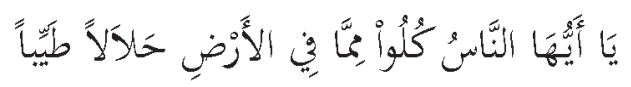

Eat of what is lawful and wholesome on the earth. ${ }^{14}$

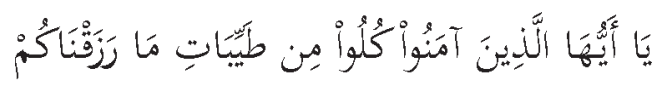

Eat of the good things which we have provided for you. ${ }^{15}$

A hadith of the Prophet Muhammad aلd wivente illustrates the importance of whole grains over refined 
flour:

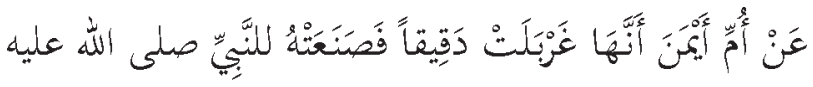

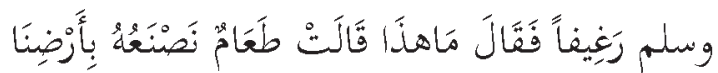

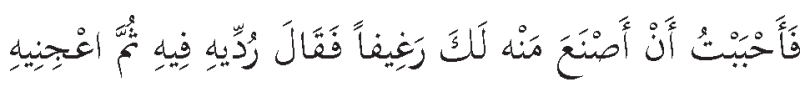

Umm Ayman once refined flour to bake bread for the Prophet على che asked her what she was doing, and she replied: "This is a type of food which we used to make back home, and I thought of baking it for you." The Messenger صلئل sald, "Put it (the bran) back in, then make the dough." 16,17

The USDA and HHS issue national guidelines for diet and nutrition every five years based on the latest scientific evidence. The Dietary Guidelines for Americans, 2010, is a prerequisite for the federal nutritional assistance program. ${ }^{18}$

The nutrient standards for healthful school meals specify target goals for key nutrients for different groups of children. Foods that naturally contain these nutrients also typically contain other essential nutrients not specified in the nutrient standards. Nutrition requirements target goals for school lunches to provide one-third of the recommended dietary allowances of protein, vitamin A, vitamin C, iron, calcium, and calories. The fat content in lunches must meet the applicable recommendations of the Dietary Guidelines for Americans, which states that total fat intake is kept from 30 to 35 percent of calories for children 2 to 3 years of age and from 25 to 35 percent of calories for children and adolescents 4 to 18 years of age, with calories from saturated fat less than 10 percent. It is recommended that most fats come from polyunsaturated and monounsaturated fatty acid sources, such as fish, nuts, and vegetable oils. Trans fatty acid consumption should be kept as low as possible by limiting foods that contain synthetic sources of trans fats, such as partially hydrogenated oils, and by limiting other solid fats. Oils should replace solid fats where possible. ${ }^{18}$

Children and adolescents are also encouraged to consume wholegrain products often. At least half the grains served should be whole grains. Whole-grain wheat, corn, oats, and brown rice provide fiber and other nutrients. Foods made from grains are naturally low in fat unless fat is added during processing or as an ingredient in a recipe. Substituting whole grains for refined grains in foods such as bread, tor- tillas, taco shells, and breakfast cereals is an easy way to increase fiber in the menus. The consumption of foods that contain refined grains, especially those containing solid fats, added sugars, and sodium, should be limited.

Vegetables are a key part of a daily diet and provide vitamins, minerals, and fiber. Most are low in fat and calories, while also filling. A variety of vegetables are important because different vegetables are rich in different nutrients. Weekly intake of specific amounts from each vegetable subgroup (dark green, orange, legumes [dry beans], starchy, and other vegetables) is recommended for adequate nutrient intake. To help meet this recommendation, schools should offer more:

- Fruits, which are good sources of potassium, fiber, vitamin C, and folic acid; are naturally low in fat, sodium, and calories; and have no cholesterol. To help ensure adequate fiber intake, fruits (fresh, frozen, canned, dried) rather than fruit juice are recommended for most of the fruit servings. For most children and adolescents, intake of 100 percent fruit juice is not associated with weight gain. However, limited evidence suggests that increased intake of 100 percent juice has been associated with higher body weight in children and adolescents who are already overweight or obese. 18

- Sugar-sweetened beverages provide excess calories and few essential nutrients to the diet, and should not be offered by schools. Recent data reveals that children and adolescents who consume more sugar-sweetened beverages have higher weight compared to those who drink less. ${ }^{18}$ Milk products and fortified soy beverages are calcium-rich foods and provide protein and other vitamins that are key to growth and development. Children 2 to 8 years should consume two cups per day of fat-free or low-fat milk or equivalent milk products, while children 9 years of age and older should consume three cups per day of fat-free or low-fat milk or equivalent milk products.

- Lean meat, poultry, seafood, dry beans or peas, eggs, soy products, unsalted nuts, and seeds are protein rich foods. Fish, nuts, and seeds help to provide healthful oils within the diet. Varying choices of protein sources daily can help limit 
excess saturated fat and cholesterol. In order to meet these guidelines, schools should offer a variety of fruits and vegetables as well as foods with good sources of protein. Attention should also be given to proper serving sizes.

\section{Culture of Healthful Eating}

The school environment is a good place to instill the culture of consuming healthful foods and avoiding junk foods, which are also known as foods of minimal nutritional value (FMNV). ${ }^{19}$ The USDA defines FMNV as foods that provide less than 5 percent of the United States Recommended Daily Allowance (USRDA) for each of the eight specified nutrients per 100 calories and less than 5 percent of the USRDA for each of eight specified nutrients per serving. The eight specified nutrients to be evaluated are protein, vitamin A, vitamin C (ascorbic acid), niacin, riboflavin, thiamin, calcium, and iron.

USDA has identified four categories of food items that are considered to be FMNV:

1. Soda water: Any carbonated beverage. No product shall be excluded from this definition because it contains discrete nutrients added to the food such as vitamins, minerals and protein.

2. Water ices: Any frozen, sweetened water such as popsicles and flavored ice with the exception of products that contain fruit or fruit juice.

3. Chewing gum: Any flavored products from natural/synthetic gums and other ingredients that form an insoluble mass for chewing.

4. Certain candies: Any processed foods made predominantly from sweeteners or artificial sweeteners with a variety of minor ingredients that characterize the following types:
a) Hard candy
b) Jellies and gums
c) Marshmallow candies
d) Fondant
e) Licorice
f) Spun candy
g) Candy-coated popcorn

Although federal regulations prohibiting the sale and advertisement of FMNV are currently being considered, the USDA and World Health Organization (WHO) both recommend banning all FMNV in schools. A 2010 University of Nebraska-Lincoln study reported that eliminating junk foods from lunch a la carte lines produced an 18-percent reduction in student obesity. ${ }^{20}$ Parents should also be encouraged to not include these foods in their child's packed lunches as well.

Schools should establish written nutrition policies detailing appropriate and acceptable foods for students, as well as foods that are prohibited from being consumed on campus. Parents must be notified of these policies to assist in their implementation. A sample policy statement (Appendix 4) and listing of appropriate and inappropriate food and drinks for such a policy adapted from Brighter Horizons Academy Nutrition Policy is provided (Appendix 5).

\section{Funding for Islamic School Lunch Programs}

The cost of quality ingredients and the equipment used to prepare meals can limit Islamic schools' ability to implement current guidelines. Various sources of funding are available to schools; however, some may be restricted by eligibility requirements.

Most schools throughout the United States participate in the National School Lunch Program, a federally assisted meal program operating in public and nonprofit private schools and residential child-care institutions. Schools that participate in the National School Lunch Program must provide nutritionally balanced, reduced-cost, or free lunches to eligible students each school day. Students from low-income families who are at or below 130 percent of the federal poverty guidelines are eligible for free meals. Those between 130-185 percent of the federal poverty guidelines are eligible for a reduced price. ${ }^{9}$ Schools receive a reimbursement for every meal provided. Reimbursement of meal costs provides schools financial assistance in their lunch programs. Schools also have the opportunity to apply for federal grants that provide additional funding for their lunch program.

Grants are also available to schools regardless of participation in the National School Lunch Program. These grants are intended to help schools focus on a specific area of their lunch program, such as increasing menu options that are more healthful or improving lunch service equipment.

The availability of funding for Islamic school lunch programs can vary based on many factors, including the percentage of students from lowincome households, the total number of meals prepared daily, and the ability of schools to implement 
local and federal guidelines when preparing and serving meals on site.

Information on funding for school lunch programs can be found at the following web sites:

- http://healthymeals.nal.usda.gov

- http://www.healthyeatingresearch.org

- http://www.loveyourveggies.com/ school_grants.php

\section{Conclusion}

The school food environment provides an important and feasible opportunity to improve children's diets and health behavior. ${ }^{21}$ By encouraging Islamic schools to implement the Dietary Guidelines for Americans, 2010, IMANA seeks to improve the health and success of Muslim children. Due to the diverse ethnic background of Islamic school students, consideration must be given to cultural food preferences while still providing a diet rich with fruits, vegetables, whole grains, lean protein, and low in fat. Funding for school lunch programs is available by participation in the National School Lunch Program or by applying for grants. Studies have shown that schools, both public and private, can play a vital role in influencing the dietary habits of students. ${ }^{22}$ Key factors include eliminating foods of minimal nutritional value served during school lunch and educating parents on providing healthful home-packed lunches. However, offering nutritious foods may be even more effective when coupled with nutrition education and strong school wellness policies. ${ }^{23}$ By educating children and parents, Islamic schools can create a healthier future for the nation's Muslims.

\section{Reference}

1. The Pew Forum on Religion \& Public Life. Mapping the global Muslim population: a report on the size and distribution of the world's Muslim population. Washington, DC: Pew Research Center; 2009. http://pewforum.org/Mapping-the-Global-MuslimPopulation.aspx

2. Ogden CL, Carroll MD, Curtin LR, et al. Prevalence of high body mass index in U.S. children and adolescents, 2007-2008. JAMA. 2010;303:242-9. http://dx.doi.org/10.1001/jama.2009.2012

3. Nicklas T, Johnson R; American Dietetic Association. Position of the American Dietetic Association: dietary guidance for healthy children ages 2-11 years. J Am Diet Assoc. 2004:104;660-77. http://dx.doi.org/10.1016/j.jada.2004.01.030

4. U.S. Department of Health and Human Services. The Surgeon General's call to action to prevent and decrease overweight and obesity. Rockville, MD: U.S. Department of Health and Human Services, Public Health Service, Office of the Surgeon General; 2001. http://www.surgeongeneral.gov/ topics/obesity/calltoaction/toc.htm

5. Taras H. Nutrition and student performance at school. J Sch Health. 2005;75:199-213. http://dx.doi.org/10.1111/i.1746-1561.2005.00025.x 6. Bergman EA, Gordon RW; American Dietetic Association. Position of the American Dietetic Association: local support for nutrition integrity in schools. J Am Diet Assoc. 2010;110:1244-54. http://dx.doi.org/10.1016/i.jada.2010.06.014

7. Kubik MY, Lytle L, Fulkerson JA. Physical activity, dietary practices, and other health behaviors of atrisk youth attending alternative high schools. J Sch Health. 2004;74:119-24. http://dx.doi.org/ 10.1111/j.1746-1561.2004.tb06613.x

8. Islamic Schools, Muslim Schools in USA [Internet]. [Cited 2011 June 4]. http://www.indianpakistani.net/islamic+schools/

9. United States Department of Agriculture. Food and Nutrition Service. National School Lunch Program. [Cited 2011 June 4]. http://www.fns. usda.gov/cnd/lunch/

10. Massacusetts Department of Elementary \& Secondary Education. Nutrition, health and safety [Internet]. [Cited 2011 June 4]. http://www.doe. mass.edu/cnp/nprograms/nslp.html

11. School Meals [Internet]. [cited 2011 June 4]. http://www.fns.usda.gov/cnd/menu/menu.plannin g.NSLP.htm

12. United States Department of Agriculture. Food and Nutrition Service. Menu planner for healthy school meals. [Cited 2011 June 4].

\begin{tabular}{lllllllllllllllll}
$h$ & $t$ & $t$ & $p$ & $:$ & $/$ & $/$ & $t$ & $e$ & $a$ & $m$ & $n$ & $u$ & $t$ & $r$ & $i$ \\
\hline
\end{tabular}

tion.usda.gov/Resources/menuplanner.html

13. United States Department of Agriculture. Food and Nutrition Service. Meal Patterns. [Cited 2011 June 4]. http://www.fns.usda.gov/cnd/care/progra mbasics/meals/meal patterns.htm

14. The Glorious Qur'an Chapter 2, Verse 168.

15. The Glorious Qur'an Chapter 2, Verse 173.

16. Sunan Ibn Mājah. Kitāb al-aț ma. Bāb al-ḥuwwārī. Hadith no. 3336. http://muhaddith.org. 17. Al-Khayat MH. Health: an Islamic Perspective. 
Alexandria, Egypt: World Health Organization. http://dx.doi.org/10.1509/jppm.29.2.204

Regional office for the Eastern Mediterranean; 1997. http://www.emro.who.int/Publications/Book Detai Is.asp?ID $=55$

18. U.S. Department of Agriculture and U.S. Department of Health and Human Services. Dietary guidelines for Americans, 2010. 7th Edition. Washington, DC: U.S. Government Printing Office; December 2010. http://www.cnpp. usda.gov/Publications/DietaryGuidelines/2010/Poli cyDoc/PolicyDoc.pdf

19. Story M, Nanney MS, Schwartz MB. Schools and obesity prevention: creating school environments and policies to promote healthy eating and physical activity. Milbank Q. 2009;87:71-100. http://dx.doi.org/10.1111/j.1468-0009.2009.00548.x 20. Dority BL, McGarvey MG, Kennedy PF. Marketing foods and beverages in schools: the effect of school food policy on students' overweight measures. Journal of Public Policy \& Marketing. 2010;29:204-18.

21. Briefel RR, Wilson A, Gleason PM. Consumption of low-nutrient, energy-dense foods and beverages at school, home, and other locations among school lunch participants and nonparticipants. J Am Diet Assoc. $\quad 2009 ; 109(2 \quad$ Suppl):S79-90. http://dx.doi.org/10.1016/j.jada.2008.10.064 22. Cullen KW, Zakeri I. Fruits, vegetables, milk, and sweetened beverages consumption and access to à la carte/snack bar meals at school. Am J of Public Health. 2004;94:463-7. http://dx.doi.org/10.2105/AJPH.94.3.463

23. Greece JA, Ozonoff A, Tao W, et al. Effect of a school-based healthy eating intervention on overall food and nutrient intake in minority, low socioeconomic status middle school children. J Am Diet Assoc. 2010;110(9S1):A97. http://dx.doi.org/10.1016/j.jada.2010.06.362

\section{Appendix 1: Islamic School Lunch Survey Questionnaire}

School Name:

Address:

Phone:

Contact Person:

Questions

1) Does your school serve lunch?

2) If no to question 1: do you provide any

guidelines for what foods parents should include in lunch?

3) Do you have a set menu?

4) If yes, would you provide a copy of the menu for the week?

5) Does the menu follow any standard guidelines?

6) Do you have a dietician who advises/creates lunch menus?

7) Do you serve American food?

8) Do you serve ethnic food?

9) Would you be interested in receiving a summary of the survey?

10) Would you be interested in receiving a proposed nutritionally balanced dietician recommended menu of American and ethnic food?

$\begin{array}{lll}\mathrm{Y} & \mathrm{N} & \\ \mathrm{Y} & \mathrm{N} & \text { N/A } \\ & & \\ \mathrm{Y} & \mathrm{N} & \text { N/A } \\ \mathrm{Y} & \mathrm{N} & \text { N/A } \\ \mathrm{Y} & \mathrm{N} & \text { N/A } \\ \mathrm{Y} & \mathrm{N} & \text { N/A } \\ \mathrm{Y} & \mathrm{N} & \text { N/A } \\ \mathrm{Y} & \mathrm{N} & \text { N/A } \\ \mathrm{Y} & \mathrm{N} & \\ \mathrm{Y} & \mathrm{N} & \end{array}$


Appendix 2: Minimum Nutritional Requirements for School Lunches

\begin{tabular}{|c|c|c|c|}
\hline $\begin{array}{l}\text { Nutrient Needs and Energy } \\
\text { Allowances }\end{array}$ & Preschool & Grades K-6 & Grades 7-12 \\
\hline Energy allowances (calories) & 517 & 664 & 825 \\
\hline $\begin{array}{l}\text { Total fat (as a percentage of actual total } \\
\text { food energy) }\end{array}$ & $<30 \%$ & $<30 \%$ & $<30 \%$ \\
\hline $\mathrm{RDA}^{*}$ for protein $(\mathrm{g})$ & 7 & 10 & 16 \\
\hline RDA for calcium (mg) & 267 & 286 & 400 \\
\hline RDA for iron (mg) & 3.3 & 3.5 & 4.5 \\
\hline RDA for Vitamin A (Retinol Equivalents) & 150 & 224 & 300 \\
\hline RDA for Vitamin C (mg) & 14 & 15 & 18 \\
\hline \multicolumn{4}{|l|}{ Food Components and Items } \\
\hline 1 Milk (as a beverage) & 6 fluid ounces & 8 fluid ounces & 8 fluid ounces \\
\hline 1 Meat or Meat Alternative & $11 / 2$ ounces & 2 ounces & 2 ounces \\
\hline lean meat, poultry or fish ${ }^{2}$ & $11 / 2$ ounces & 2 ounces & 2 ounces \\
\hline alternate protein product & $11 / 2$ ounces & 2 ounces & 2 ounces \\
\hline cheese & $11 / 2$ ounces & 2 ounces & 2 ounces \\
\hline large egg & $3 / 4$ egg & 1 egg & 1 egg \\
\hline cooked dry beans or peas & $3 / 8$ cup & $1 / 2$ cup & $1 / 2$ cup \\
\hline peanut or other nut or seed butters & 3 Tablespoons & 4 Tablespoons & 4 Tablespoons \\
\hline nuts and/or seeds ${ }^{3}$ & $3 / 4$ ounce & 1 ounce & 1 ounce \\
\hline yogurt & $3 / 4$ cup & 1 cup & 1 cup \\
\hline 2 Vegetables or Fruits ${ }^{4}$ & $1 / 2$ cup & $3 / 4$ cup & 1 cup \\
\hline $\begin{array}{l}1 \text { Grains/Breads }{ }^{5} \text { (servings per } \\
\text { school week) }\end{array}$ & 8/week & 10-12/week & $10-15 /$ week \\
\hline bread & $1 / 2$ slice & 1 slice & 1 slice \\
\hline cornbread, biscuit, roll or muffin & $1 / 2$ serving & 1 serving & 1 serving \\
\hline
\end{tabular}

1 Fewer than 10 percent of calories from saturated fat over a school week.

2 A serving consists of the edible portion of cooked lean meat, poultry or fish.

3 Nuts and seeds may meet only one-half of the total meat/meat alternate servings and must be combined with another meat/meat alternate to fulfill the lunch requirement.

4 Fruit or vegetable juice must be full strength.

5 Breads and grains must be made from whole-grain or enriched meal or flour. Cereal must be whole grain, enriched or fortified.

*Recommended Daily Allowance (RDA) 
Entrées

Vegetable pita pocket with cheese and vegetables (sliced cucumbers, shredded carrots, tomatoes, lettuce); Tuna salad; Egg salad; Hummus dip with vegetables and pita; Black bean soup and Cheese cubes; Cheese quesadilla triangles; Chicken stir fry with vegetables; Whole-wheat spaghetti with meat sauce; Lentil soup; Toasted cheese sandwich; Baked chicken; Hamburger on whole grain bun; Crunchy coated baked fish; Ovenfried chicken; Soft chicken taco with cheese, shredded lettuce and diced tomato; Whole-wheat pita pizza with cheese and vegetables - tomatoes, mushrooms, green peppers, olives; Fish Sticks; Chicken kabobs; Chicken shawerma wraps; Chicken curry; Chickpea curry/Chana masala; Ful mudammas and pita; Falafel sandwich with lettuce, cucumber and tomato; Hummus sandwich with lettuce, tomato and cucumber; Spanakopita (spinach and cheese pockets); Kofta wrap with whole wheat pita; Tandoori chicken; Chicken tikka; Vegetable curry with brown rice

\section{Grains}

Whole wheat pita; Whole grain rolls; Whole wheat bread; Whole wheat tortillas; Steamed brown rice; Whole wheat pasta; Whole-grain crackers; Whole-wheat buns; Couscous; Egg noodles; Cornbread; Rice pilaf; Tabbouleh; Bulgur; Mujadara; Kitchari; Kusheri; Whole wheat chappati/roti; Naan; Lentil salad

\section{Vegetables}

Raw vegetables - Carrot sticks, broccoli, zucchini, green pepper strips and low-fat dip; Carrot raisin salad; Shredded carrots; Marinated vegetable salad; Spinach salad; Garden salad; Cucumber tomato salad; Confetti coleslaw; Baked potatoes; Baked sweet potato fries; Mixed vegetables; Corn; Red cabbage slaw; Steamed broccoli; Steamed green beans; Steamed carrot coins; Peas; Potato and cauliflower curry (Aloo gobi); Spinach and potato curry (Aloo saag); Roasted potatoes; Roasted vegetables - squash, peppers, zucchini, asparagus, sweet potatoes

\section{Fruit}

Pineapple chunks; Pear; Apricots in juice; Orange segments; Clementine; Sliced kiwi; Mango slices; Banana; Cantaloupe chunks; Plums; Blueberries; Strawberries; Watermelon; Nectarine; Peaches; Applesauce; Apple slices; Melon; Grapes; Mixed fruit salad 


\title{
Appendix 4: Nutrition Policy Statement Suggestions
}

- Follow USDA guidelines for school lunches.

- Cafeteria should maintain a clean atmosphere and provide hand-washing stations.

- Adequate time should be allowed for students to receive and consume meals, with a minimum of 20 minutes for lunch.

- Whenever possible, physical activity and recess should be scheduled before lunch.

- Packed lunches from home must comply with the guidelines. Parents shall provide a healthful and nutritious packed lunch for their child, which may not contain any FMNV or consist of candy, chips or dessert type items (cookies, cakes, cupcakes, pudding, ice cream or frozen desserts, etc). Any items not in compliances will be confiscated and parents will be notified.

- Do not serve or provide access to FMNV at any time anywhere on school premises, including school lunch program and snack tables, until the end of the last scheduled class and/or after school activity. Appendix 3 lists the FMNV restricted foods.

- Teachers and/or staff may not give FMNV as rewards/snacks to any student anytime on school premises and are encouraged to use non-food items as rewards. Food may be used for instructional purposes as long as the food item is not considered FMNV or candy.

\section{Appendix 5: Appropriate and Inappropriate Food and Drink Items}

\section{Appendix 5a: Drinks}

\author{
Appropriate \\ Water \\ 100 percent fruit juice \\ Minute Maid 100 percent/ \\ Juicy Juice 100 percent \\ Tropicana 100 percent juice \\ (variety flavors) \\ Disney Hundred Acre Wood 100 percent \\ Milk \\ Motts 100 percent \\ Tree Top \\ odwalla \\ Naked Juice \\ Kirkland 100 percent juice (vitamin fortified) \\ Not Appropriate \\ Carbonated Beverages/Flavored Water/Sugar Water \\ Minute Maid Coolers \\ Tropicana Twister \\ Capri Sun \\ Kool-Aid/Hi-C \\ Sunny Delight \\ Hawaiian Punch/Iced Tea \\ Crystal Light/Country Time Lemonade \\ Energy Drinks \\ Gatorade \\ Soda
}

Wordings such as "drinks," "cocktails," "coolers," "all natural'" does not necessarily mean 100 percent juice eg. Capri Sun, nor does it preclude the addition of high fructose corn syrup. 


\section{Appendix 5b: Snacks}

This involves cookies, crackers, chips, nuts, and bars. The aim is to reduce high fat and high sugar foods as recommended by the daily nutrition guidelines.

\section{Appropriate}

Pretzels

Triscuits

Wheat Thins

Pita chips

Rice cakes

Whole grain crackers

Rye crispbread

Nuts (beware of allergies)

Whole grain graham crackers

Fig Newtons/fruit leathers

Granola bars (Nature Valley, Luna, Odwalla, Quaker)

Whole grain animal crackers

Whole grain gold fish crackers

Homemade muffins/loaves; Banana bread etc (not packaged)

Sun Chips - Original Flavor, Salsa

Cheez-Its

Chex Mix

Unflavored popcorn

\section{Not Appropriate}

Packaged Donuts

100 Calorie Packs

Snackwells

Cereal Bars

Pop Tarts

Fruit Roll Ups

Gummy Fruit Snacks

Little Debbie's

Packaged cookies

Potato chips

Milk and cereal bars

Doritos

Fritos

Cakes/cupcakes

Pringles

Cheetos

candy

Saltines, Ritz Crackers

\section{Appendix 5c: Lunches}

These are suggested and appropriate examples that can assist in preparation for a healthy lunch. The aim is to increase the consumption of fruit, vegetables, protein, and complex carbohydrates, while reducing the consumption of simple sugars and fats. Also it is important to note that many of these packaged products contain additives, such as MSG and artificial colors.

\section{Appropriate}

Mashed potato

Vegetables

Fruit

Pita pockets

Wraps/tortillas

Pasta/rice

Salad

Chicken/meatloaf/homemade dinner

Low fat yogurts (Yoplait, Dannon, Stoneyfield, etc.)

Fruit cups (unsweetened or in own juice)

Cheese (low fat)

Bread (whole wheat, whole grain)

\section{Not Appropriate}

Ramen Noodles/Cup O'Soup

Hot Pockets/Lean Pockets

Lunchables

Stouffers

Kraft Mac and Cheese/Easy Mac

Go Gurt

Trix Yogurt

Drinkable Yogurt

Pudding

Jell-O

Canned Pasta (eg. Chef Boyardee) 